include data on exposure category, age, sex, and postcode in their reports of positive test results. In Riverside a comprehensive request form for the test is being introduced to ensure that each laboratory can report the relevant epidemiological data.

We thank the following clinicians and microbiologists for their cooperation and support during the study: $\mathrm{Dr} \mathrm{J} \mathrm{C}$ Coleman, Dr B A Evans, Dr B Gazzard, Professor A Guz, Dr D A Hawkins, Dr L Howard, Dr A G Lawrence, Dr K A
McClean, Dr I M Murray-Lyon, Dr P L Samarasinghe, and Dr D C Shanson.

1 Gill ON, Adler MW, Day NE. Monitoring the prevalence of HIV: foundations for a programme of unlinked anonymous testing in England and Wales. $B M \mathcal{J}$ for a programme

2 Duff $C$, Hutchby JP. Surveillance of AIDS cases: How acceptable are the figures? BMJ 1988;297:965.

3 Bobby JJ, Spencer PD, Wyatt JC, Farmer RDT. AIDS deaths in the UKHow complete are the figures? Public Health 1988;102:519-24.

$4 \mathrm{McCormick} A$. Estimating the size of the HIV epidemic by using mortality data. Philos Trans R Soc Lond (Biol) 1989;325:163-73.

(Accepted 5 March 1991)

\title{
Characteristics of general practitioners who did not claim the first postgraduate education allowance
}

\section{T S Murray, G S Dyker, L M Campbell}

\section{West of Scotland Committee for Postgraduate Medical Education, University of Glasgow, Glasgow G12 8QQ \\ T S Murray, FRCGP, adviser in general practice G S Dyker, FRCGP, deputy adviser in general practice L M Campbell, MRCGP, assistant adviser in assessment \\ Correspondence to: Dr Murray.}

BMF 1991;302:1377
Attendance by general practitioners at postgraduate meetings fell when such attendances ceased to be obligatory for seniority payments, ${ }^{1}$ and studies of nonattenders have not shown definite trends. ${ }^{1-3}$ The 1990 contract includes a postgraduate education allowance, which is paid as part of the statement of fees and allowances ${ }^{4}$; a general practitioner needed to have completed 10 sessions of accredited education between 1 April 1989 and 30 September 1990 to obtain the first allowance.

The West of Scotland Committee for Postgraduate Medical Education has set up a computerised database that records all attendances by doctors at accredited meetings both within and outwith the region (T S Murray et al, unpublished report). The region comprises six health boards and includes 1802 general practitioners serving $2 \cdot 8$ million patients. We studied the characteristics of the general practitioners in the region who were not eligible to claim for the education allowance.

\section{Methods and results}

A printout was obtained from the database on 31 December 1990 of all general practitioners in the west of Scotland who had attended fewer than 10 sessions of accredited education. The latest editions of the Medical Register, the General Medical Council list, and the health board lists were used to determine the data of qualification, membership of the Royal College of General Practitioners, and the structure of each doctor's practice.

A total of 102 doctors had attended insufficient sessions to claim the allowance; all of them had attended two or fewer sessions. Their distribution among the six health boards is shown in the table. Of

Numbers (percentages) of general practitioners not eligible for postgraduate education allowance in west of Scotland by health board

\begin{tabular}{lcr}
\hline Health boards & Total & $\begin{array}{r}\text { Not eligible } \\
\text { for allowance }\end{array}$ \\
\hline Greater Glasgow & 653 & $42(6 \cdot 4)$ \\
Lanarkshire & 300 & $16(5 \cdot 3)$ \\
Argyll and Clyde & 307 & $17(5 \cdot 5)$ \\
Ayrshire and Arran & 252 & $14(5 \cdot 6)$ \\
Dumfries and Galloway & 104 & $4(3 \cdot 8)$ \\
Forth Valley & 186 & $9(4 \cdot 8)$ \\
\hline Total & 1802 & $102(5 \cdot 7)$ \\
\hline
\end{tabular}

the 102,18 were women and 14 were members of the royal college. Fifty three were in a single handed or a two person practice, and 38 had been qualified for over 30 years. The distance from an educational centre did not seem to affect attendance at accredited sessions as only 20 of the general practitioners were based more than $16 \mathrm{~km}$ from one. The policy of the practice seemed to be important, however, as 48 doctors came from 38 practices.

\section{Comment}

The general practitioners most in need of postgraduate education took the least part in it: doctors in small practices, for example, need to share experiences with their peers. Those ineligible for the allowance had obviously consciously decided not to attend accredited sessions as they had all accrued a maximum of only two.

General practitioners were initially concerned that the time spent away from the practice, the course fees, and the lack of reimbursement of travel and subsistence costs would make postgraduate education not cost effective under the new contract. The fact that almost $95 \%$ of doctors fulfilled the requirements suggests, however, that the postgraduate education allowance is one of the successes of the 1990 contract. Only a few general practitioners were based far from a centre, and the fears that attendance would fall with the removal of the travel and subsistence budget have not been justified. Interestingly, Greater Glasgow has the highest concentration of general practitioners and the highest proportion of doctors who did not claim the allowance.

The length of time since qualification was important. Those who had been qualified for some time might have been overwhelmed by the changes in the contract and not had sufficient time to follow their educational requirements. Some might have been preparing for retirement and others might have taken a 24 hour retirement in which the money that they could earn thereafter was restricted.

Our study has shown some interesting characteristics of general practitioners who did not claim the postgraduate education allowance. The high uptake of this allowance is encouraging, but work is required to ensure that the quality of the material presented is worth while and relevant to general practitioners' day to day practice.

\footnotetext{
1 Wood J, Byrne PS. Section 63 activities. London: Royal College of General Practitioners, 1980. (Occasional Paper 11.)

2 Reedy BLEC. General practitioners and postgraduate education in the Northerm region. London: Royal College of General Practitioners, 1979. (Occasional Paper 9.)

3 Branthwaite A, Ross A, Henshaw A, Davie C. Continuing education for general practitioners. London: Royal College of General Practitioners, 1988. (Occasional Paper 38.)

4 Department of Health and Welsh Office. General practice and the National Health Service. A new contract. London: Department of Health, 1989. 